\title{
Etiological Spectrum of Pregnancy-Related Acute Renal Failure among Females at a Tertiary Care Hospital
}

\author{
Syed Muhammad Muzaffar Hussain 1, Khalid Mahmood Nasir 2, Qazi Adil Inam 3, Khalid Mahmud Khan 4 \\ ${ }_{1}$ PGR Medical Unit 1, Allama Iqbal Medical College/Jinnah Hospital, Lahore \\ ${ }^{2}$ Assistant Professor, Medical Unit 1, Allama Iqbal Medical College/Jinnah Hospital, Lahore \\ ${ }^{3}$ Associate Professor of Urology, Nawaz Sharif Medical College, Gujrat \\ ${ }^{4}$ Associate Professor, Medical Unit 1, Allama Iqbal Medical college/Jinnah Hospital, Lahore
}

\section{ABSTRACT}

\begin{abstract}
Background: Acute renal failure in pregnancy can be induced by any of the disorders leading to renal failure in the general population, such as acute tubular necrosis due to infection, glomerulonephritis related to lupus, or drug toxicity. There are, however, pregnancy complications characteristic of each trimester that can result in renal failure. The objective of this study was to determine the frequency of various causes of pregnancy-related acute renal failure among females presenting to a tertiary care hospital.
\end{abstract}

Material and Methods: This cross-sectional study was conducted in Jinnah hospital, Lahore from January to August, 2017. A total of 110 patients with pregnancy-related acute renal failure presenting to the labour room were enrolled in this study. Demographic data and history of antepartum and postpartum haemorrhage or bleeding from any site of the body were noted. Patients having sepsis, disseminated intravascular coagulation (DIC), acute fatty liver of pregnancy, HELLP syndrome, pregnancyinduced hypertension $(\mathrm{PIH})$ and preeclampsia were noted. Data was stratified for age of females and parity to control any effect modifier and chi-square test was applied post-stratification, taking $p$-value $<0.05$ as significant.

Results: Among 110 patients, the mean for age was $29.27 \pm 8.40$ years, for parity was $4.03 \pm 2.01$, and for BMl was $24.05 \pm 3.94$ $\mathrm{kg} / \mathrm{m}^{2}$. Antepartum hemorrhage was present in $25.5 \%$ patients, post-partum hemorrhage in $21.8 \%$, sepsis in $48.2 \%$, DIC in $16.4 \%$, acute fatty liver of pregnancy in $11.8 \%$, PIH in $53.6 \%$, pre-eclampsia in $55.5 \%$, HELLP syndrome in $12.7 \%$ and intrauterine death of the fetus in $14.5 \%$ patients. Age was significantly associated with DIC $(p=0.006)$ and Intrauterine death of the fetus $(p=0.020)$. Antepartum hemorrhage $(p=0.014)$ and DIC were significantly associated with parity $(p=0.022)$.

Conclusion: Antepartum haemorrhage was found to be the most common etiological factor causing pregnancy-related acute renal failure, followed by post-partum hemorrhage.

Key words: Antepartum hemorrhage, HELLP syndrome, Pregnancy-related ARF, Preeclampsia, Post-partum hemorrhage

Authors' Contribution:

1,2 Conception, synthesis, planning of research and manuscript writing 3,4 Interpretation, discussion, Data analysis, Active participation in data collection.

Cite this article: Hussain SM, Nasir KM, Inam QA, Khan KM. Etiological spectrum of pregnancy related acute renal failure females presenting to tertiary care hospital. J Islamabad Med Dental Coll.2019; 8(1):13-17

\section{Introduction}

Acute renal failure in pregnancy can be induced by any of the disorders leading to renal failure in the general population, such as acute tubular necrosis due to infection, glomerulonephritis related to lupus, or drug toxicity. There are however, pregnancy complications characteristic of each trimester, that can result in renal failure. ${ }^{1}$ Early in pregnancy, most common renal problems are pre-renal disease due to hyperemesis gravidarum or acute tubular necrosis, resulting from a septic abortion. Several different uncommon disorders can lead to acute renal failure later in pregnancy 1,2

Mild to moderate preeclampsia is not part of this differential diagnosis since the renal function is generally 
maintained in the normal or near-normal range. An important and difficult differential diagnosis is that of acute renal failure in late pregnancy in association with microangiopathic hemolytic anemia and thrombocytopenia. ${ }^{3}$ Other main entities that must be considered as a cause of renal failure include thrombotic thrombocytopenic purpura hemolytic uremic syndrome (TTP HUS), severe preeclampsia, and HELLP syndrome (hemolysis with a microangiopathic blood smear, elevated liver enzymes, and a low platelet count). ${ }^{3-5}$

Women who present with significant renal failure (which is typical of syndromes described as HUS) more frequently present in the postpartum period. ${ }^{6}$ Women who present without significant renal failure (which is typical of syndromes described as TTP and often associated with severe ADAMTS13 deficiency) also most commonly present near-term or postpartum but also may occur as early as the first or second trimester. ${ }^{7}$ Severe preeclampsia is much more common than TTP-HUS and is usually preceded by characteristic clinical features of hypertension, proteinuria and occasionally edema, which can be severe. Generalized coagulopathy may be present when severe abruptio placentae, hepatic rupture, or liver failure complicate preeclampsia. Low levels of clotting factors, if present, are important diagnostically since they are almost always absent in TTP-HUS in which thrombocytopenia is usually the only hemostatic abnormality. 7,8

TTP-HUS is characterized by the otherwise unexplained combination of thrombocytopenia and microangiopathic anemia. Thrombotic microangiopathy can lead to renal failure in either pregnancy-associated TTP or HUS, though it is more prevalent among patients with HUS. Postpartum disease may follow a normal pregnancy or be preceded by findings indistinguishable from preeclampsia. 8,9 The objective of this study was to determine the frequency of various causes of pregnancyrelated acute renal failure among females presenting at our tertiary care hospital.

\section{Material and Methods}

This cross-sectional study was conducted in Jinnah Hospital, Lahore during the period of January to August,
2017. Through nonprobability consecutive sampling, 110 patients diagnosed with pregnancy-related acute renal failure presenting to the labour room of Jinnah Hospital Lahore were selected for this study after an informed written consent. Demographic data and history of vaginal bleeding (antepartum and postpartum haemorrhage) or bleeding from any site of the body (for DIC) along with all other causes of acute renal failure were noted in a predesigned proforma. Inclusion criteria included females aged 15 to 45 years, with acute renal failure due to pregnancy diagnosed during last 24 hours. Exclusion criteria included pre-existing renal disease before pregnancy (on history and medical records, urea > $50 \mathrm{mg} / \mathrm{dl}$, and Creatinine $>1.3 \mathrm{mg} / \mathrm{dl}$ ), patients with chronic kidney failure (shrunken kidney on USG) and those not willing to participate in the study.

All patients underwent a pelvic examination to confirm vaginal bleeding. Using aseptic techniques, blood samples were collected for total leukocyte count (TLC) to determine sepsis, prothrombin time (PT), activated partial thromboplastin time (APTT), and platelet count for DIC, serum bilirubin level for acute fatty liver of pregnancy and serum lactate dehydrogenase (LDH) and AST for HELLP syndrome. In case of raised TLC and history of fever, blood cultures were sent to confirm sepsis. In patients with raised blood pressure, urine analysis was done to determine proteinuria to label as $\mathrm{PIH}$ or preeclampsia. Ultrasonography was performed in case of suspicion of antepartum haemorrhage, fatty infiltration of the liver and intrauterine death (IUD) of the fetus. Confidentiality of the data was ensured.

Data was entered and analyzed using SPSS version 17.0. Numerical variables i.e. age, parity, and BMI were calculated as means and standard deviation. Qualitative variables like causes of pregnancy-related acute kidney failure i.e. antepartum hemorrhage, postpartum hemorrhage, sepsis, DIC, acute fatty liver, $\mathrm{PIH}$, preeclampsia, HELLP syndrome, IUD of the fetus were presented in the form of frequencies and percentages. Data was stratified for the age of females and parity to control any effect modifier and chi-square test was applied post-stratification taking $p$-value $<0.05$ as statistically significant. 


\section{Results}

Out of 110 patients, the mean age was 29.27 years \pm 8.40 , mean parity was $4.03 \pm 2.01$ and mean BMl was 24.05 $\mathrm{kg} / \mathrm{m}^{2} \pm 3.94$. Frequency of various complications in pregnant females presenting with acute renal failure is as follows: Antepartum hemorrhage was present in 28 $(25.5 \%)$ cases, post-partum hemorrhage in $24(21.8 \%)$, sepsis in $53(48.2 \%)$, DIC in $18(16.4 \%)$, acute fatty liver of pregnancy in $13(11.8 \%)$, PIH in $59(53.6 \%)$, preeclampsia in $61(55.5 \%)$, HELLP syndrome in 14 (12.7\%) and IUD of fetus was seen in $16(14.5 \%)$ patients (Figure 1).

Using chi-square test, no significant association of age was seen with acute fatty liver of pregnancy ( $p$-value $0.663), \quad \mathrm{PIH}$ ( $p$-value 0.585 ), pre-eclampsia ( $p$-value 0.316 ) and HELLP syndrome ( $p$-value 0.884). However, a significant association was found between age and intrauterine death of a fetus (p-value 0.020$)$. There was a significant association of parity with antepartum haemorrhage (p-value 0.014$)$ and DIC (p-value 0.022) while no significant association was seen with postpartum haemorrhage ( $p$-value 0.306 ), sepsis ( $p$-value 0.791 ), acute fatty liver of pregnancy (p-value 0.428$), \mathrm{PIH}$ (p-value 0.469$)$, pre-eclampsia ( $p$-value 0.235 ) and HELLP syndrome ( $p$-value 0.057$)$ and IUD of fetus ( $p$ value 0.395 ) (Tables I and II).

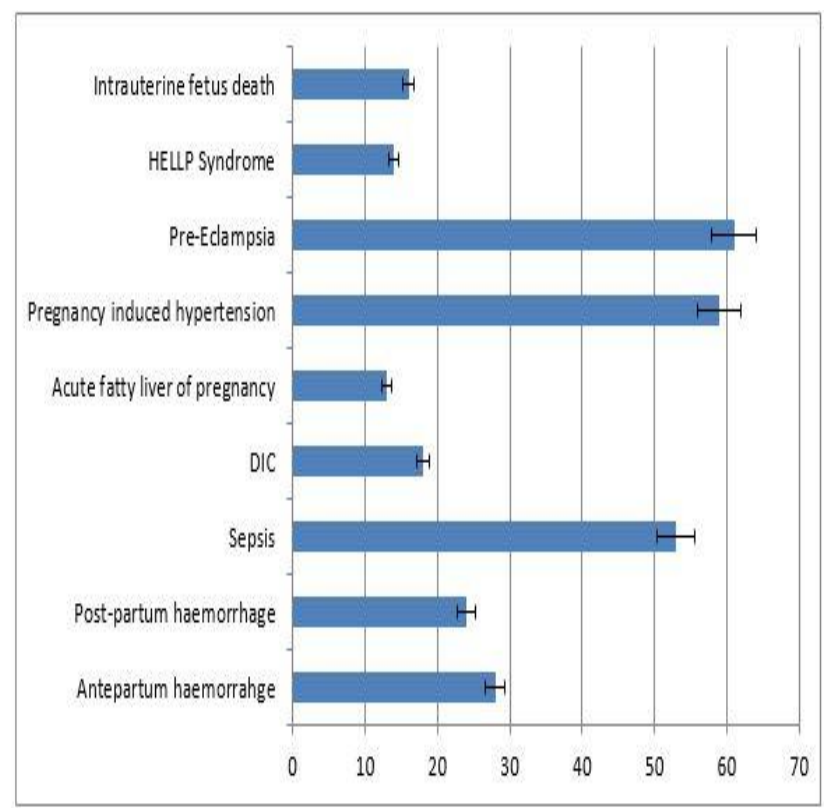

Figure: 1 Frequency of pregnancy related complications.

\begin{tabular}{|c|c|c|c|c|}
\hline \multicolumn{5}{|c|}{$\begin{array}{l}\text { Table I: Age group-wise stratification of pregnancy-related } \\
\text { complications }\end{array}$} \\
\hline \multirow[b]{2}{*}{$\begin{array}{l}\text { Age Group } \\
\text { (Year) }\end{array}$} & \multicolumn{2}{|c|}{ Antepartum haemorrhage } & \multirow[b]{2}{*}{ Total } & \multirow[b]{2}{*}{$P$ value } \\
\hline & Yes & No & & \\
\hline$<30$ & 17 & 40 & 57 & \multirow[t]{2}{*}{0.275} \\
\hline \multirow[t]{2}{*}{$\geq 30$} & 11 & 42 & 53 & \\
\hline & \multicolumn{2}{|c|}{ Post-partum haemorrhage } & & \\
\hline$<30$ & 16 & 41 & 57 & \multirow[t]{2}{*}{0.100} \\
\hline \multirow[t]{2}{*}{$\geq 30$} & 8 & 45 & 53 & \\
\hline & \multicolumn{2}{|c|}{ Sepsis } & & \\
\hline$<30$ & 25 & 32 & 57 & \multirow[t]{2}{*}{0.347} \\
\hline \multirow[t]{2}{*}{$\geq 30$} & 28 & 25 & 53 & \\
\hline & \multicolumn{2}{|c|}{ DIC } & & \\
\hline$<30$ & 4 & 53 & 57 & \multirow[t]{2}{*}{0.006} \\
\hline \multirow[t]{2}{*}{$\geq 30$} & 14 & 39 & 53 & \\
\hline & \multicolumn{2}{|c|}{ Acute fatty liver of pregnancy } & & \\
\hline$<30$ & 6 & 51 & 57 & \multirow[t]{2}{*}{0.663} \\
\hline \multirow[t]{2}{*}{$\geq 30$} & 7 & 46 & 53 & \\
\hline & \multicolumn{2}{|c|}{$\mathrm{PIH}$} & & \\
\hline$<30$ & 32 & 25 & 57 & \multirow[t]{2}{*}{0.585} \\
\hline \multirow[t]{2}{*}{$\geq 30$} & 27 & 26 & 53 & \\
\hline & \multicolumn{2}{|c|}{ Preeclampsia } & & \\
\hline$<30$ & 29 & 28 & 57 & \multirow[t]{2}{*}{0.316} \\
\hline \multirow[t]{2}{*}{$\geq 30$} & 32 & 21 & 53 & \\
\hline & \multicolumn{2}{|c|}{ HELLP Syndrome } & & \\
\hline$<30$ & 7 & 50 & 57 & \multirow[t]{2}{*}{0.884} \\
\hline \multirow[t]{2}{*}{$\geq 30$} & 7 & 46 & 53 & \\
\hline & \multicolumn{2}{|c|}{ Intrauterine fetus death } & & \\
\hline$<30$ & 4 & 53 & 57 & \multirow[t]{2}{*}{0.020} \\
\hline$\geq 30$ & 12 & 41 & 53 & \\
\hline
\end{tabular}

\begin{tabular}{|c|c|c|c|c|}
\hline \multicolumn{5}{|c|}{$\begin{array}{l}\text { Table II: Parity based stratification of pregnancy-related } \\
\text { complications }\end{array}$} \\
\hline \multirow[b]{2}{*}{ Parity } & \multicolumn{2}{|c|}{ Antepartum haemorrhage } & \multirow[b]{2}{*}{ Total } & \multirow[b]{2}{*}{$P$ value } \\
\hline & Yes & No & & \\
\hline$<4$ & 17 & 28 & 45 & \multirow[t]{2}{*}{0.014} \\
\hline$>4$ & 11 & 54 & 65 & \\
\hline \multicolumn{5}{|c|}{ Post-partum haemorrhage } \\
\hline$<4$ & 12 & 33 & 45 & \multirow[t]{2}{*}{0.306} \\
\hline$>4$ & 12 & 53 & 65 & \\
\hline \multicolumn{5}{|c|}{ Sepsis } \\
\hline$<4$ & 21 & 45 & 45 & \multirow[t]{2}{*}{0.791} \\
\hline$>4$ & 32 & 33 & 65 & \\
\hline \multicolumn{5}{|c|}{ DIC } \\
\hline$<4$ & 3 & 42 & 45 & \multirow[t]{2}{*}{0.022} \\
\hline$>4$ & 15 & 50 & 65 & \\
\hline \multicolumn{5}{|c|}{ Acute fatty liver of pregnancy } \\
\hline$<4$ & 4 & 41 & 45 & \multirow[t]{2}{*}{0.428} \\
\hline$>4$ & 9 & 56 & 65 & \\
\hline \multicolumn{5}{|c|}{ Pregnancy induced hypertension } \\
\hline$<4$ & 26 & 19 & 45 & \multirow[t]{2}{*}{0.469} \\
\hline$>4$ & 33 & 32 & 65 & \\
\hline \multicolumn{5}{|c|}{ Preeclampsia } \\
\hline$<4$ & 28 & 17 & 45 & \multirow[t]{2}{*}{0.235} \\
\hline$>4$ & 33 & 32 & 65 & \\
\hline \multicolumn{5}{|c|}{ HELLP Syndrome } \\
\hline$<4$ & 9 & 36 & 45 & \multirow[t]{2}{*}{0.057} \\
\hline$>4$ & 5 & 60 & 65 & \\
\hline \multicolumn{5}{|c|}{ Intrauterine fetus death } \\
\hline$<4$ & 5 & 40 & 45 & \multirow[t]{2}{*}{0.395} \\
\hline$>4$ & 11 & 54 & 65 & \\
\hline
\end{tabular}




\section{Discussion}

Although pregnancy-related acute renal failure is a very serious health issue, however few studies are available from Pakistan. In 1996, Naqvi and colleagues reported 18 cases of obstetrical ARF from Karachi with $23 \%$ mortality and $26 \%$ morbidity. ${ }^{10}$ The incidence of pregnancy-related acute renal failure in developed countries is $1 \%-2.8 \%$, in sharp contrast to $9 \%-25 \%$ in developing countries, mostly due to late referral of pregnancy-related complications. ${ }^{11-13}$

In Northern areas of Pakistan, obstetrical related acute renal failure was reported to be $7 \%-10 \%$ of total acute renal failure cases with $18 \%$ mortality. ${ }^{14}$

Present study reported a mean age of $29.27 \pm 8.4$ years, which is in agreement with other studies carried out in India ${ }^{12}$ and Pakistan.13,15,16 Regarding pregnancy related complications, pre-eclampsia was the commonest in our patients followed by pregnancy-induced hypertension, sepsis, antepartum hemorrhage, post-partum hemorrhage, disseminated intravascular coagulation, intrauterine death of fetus, HELLP syndrome, and acute fatty liver of pregnancy, respectively. Hassan et al reported, among 43 patients with pregnancy-related ARF, the puerperal group comprised of 36 patients (83.7\%). Hemorrhage was the etiology for ARF in $58.1 \%$ patients, followed by PPH, puerperal sepsis, APH, Pre-eclampsia, eclampsia and HELLP syndrome and DIC, respectively. ${ }^{13}$

Clinical spectrum of pregnancy-related ARF reported by Ansari et al include puerperal sepsis, septic abortion and DIC as the commonest followed by PPH, APH, IUD and pre-eclampsia / eclampsia, respectively. According to the authors, blood loss causing hypotension due to APH and $\mathrm{PPH}$ are regarded as common causes of ARF. ${ }^{15}$

Many of the pregnancy complications like pre-eclampsia / eclampsia, pregnancy induced hypertension, IUD, APH, and PPH etc. can be prevented by proper and timely antenatal check-ups and early and effective treatment strategies. ${ }^{13}$ Moreover incidence of sepsis can be effectively reduced by use of aseptic techniques during examinations and later on delivery of the baby. ${ }^{13}$

According to the present study, maternal age showed a significant association with two pregnancy complications: DIC and intrauterine death of fetus. While parity showed a significant association with antepartum haemorrhage and DIC respectively.

\section{Conclusion}

Pregnancy-related acute renal failure is a cause of concern in our hospitals. Pre-eclampsia/eclampsia was found to be the most common etiological factor causing pregnancy-related acute renal failure in our series of patients. This was followed by pregnancy-induced hypertension, sepsis, antepartum hemorrhage, postpartum hemorrhage, disseminated intravascular coagulation, intrauterine death of fetus, HELLP syndrome, and acute fatty liver of pregnancy, respectively. Effect modifiers have no significant association, except age with DIC and Intrauterine death of fetus and parity with antepartum haemorrhage and DIC.

\section{References}

1. Krane NK. Acute renal failure in pregnancy. Archives of internal medicine. 1988;148(11):2347-57.

2. Grünfeld J-P, Pertuiset N. Acute renal failure in pregnancy. American Journal of Kidney Diseases. 1987;9(4):359-62.

3. McMinn JR, George JN. Evaluation of women with clinically suspected thrombotic thrombocytopenic purpura-hemolytic uremic syndrome during pregnancy. Journal of clinical apheresis. 2001;16(4):202-9.

4. Martin JN, Blake PG, Perry KG, McCaul JF, Hess LW, Martin RW. The natural history of HELLP syndrome: patterns of disease progression and regression. American journal of obstetrics and gynecology. 1991;164(6):1500-13.

5. Sibai BM, Ramadan MK. Acute renal failure in pregnancies complicated by hemolysis, elevated liver enzymes, and low platelets. American journal of obstetrics and gynecology. 1993;168(6):1682-90.

6. Fakhouri $F$, Roumenina L, Provot $F$, Sallée $M$, Caillard S, Couzi L, et al. Pregnancy-associated hemolytic uremic syndrome revisited in the era of complement gene mutations. Journal of the American Society of Nephrology. 2010;21(5):859-67.

7. Egerman RS, Witlin AG, Friedman SA, Sibai BM. Thrombotic thrombocytopenic purpura and hemolytic uremic syndrome in pregnancy: review of 11 cases. 
American journal of obstetrics and gynecology. 1996;175(4):950-6.

8. McCrae KR, Samuels P, Schreiber AD. Pregnancyassociated thrombocytopenia: pathogenesis and management. Blood. 1992;80(11):2697-714.

9. Weiner $\mathrm{C}$. Thrombotic microangiopathy in pregnancy and the postpartum period. Semin Hematol. 1987;24:119-29.

10. Naqvi $R$, Akhtar F, Ahmed E, Shaikh R, Ahmed $Z$, Naqvi $A$, et al. Acute renal failure of obstetrical origin during 1994 at one center. Renal failure. 1996;18(4):681-3.

11. Prakash J, Tripathi K, Pandey L, Sahai S, Srivastava $P$. Spectrum of renal cortical necrosis in acute renal failure in eastern India. Postgraduate medical journal. 1995;71(834):208-10.

12. Goplani K, Shah P, Gera D, Gumber M, Dabhi M, Feroz A, et al. Pregnancy-related acute renal failure:
A single-center experience. Indian journal of nephrology. 2008;18(1):17.

13. Hassan I, Junejo AM, Dawani ML. Etiology and outcome of acute renal failure in pregnancy. $\mathrm{J}$ Coll Physicians Surg Pak. 2009;19(11):714-7.

14. Ali A, Zafar S, Mehmood A, Nisar A. Obstetrical Acute Renal Failure From Frontier Province: A 3 years prospective study. Journal of Postgraduate Medical Institute (Peshawar-Pakistan). 2011;18(1).

15. Ansari MR, Laghari MS, Solangi KB. Acute renal failure in pregnancy: one year observational study at Liaquat University Hospital, Hyderabad. JPMA The Journal of the Pakistan Medical Association. 2008;58(2):61.

16. Erdemoğlu M, Kuyumcuoğlu U, Kale A, Akdeniz N. Pregnancy-related acute renal failure in the southeast region of Turkey: analysis of 75 cases. Clinical and experimental obstetrics \& gynecology. 2009;37(2):148-9. 